\title{
Use of Big Data to Determine the Effect of Parental Educational Level on the Quality of College Students' Employment
}

\author{
Xingyan $\mathrm{Du}^{*}$, SupingChen \\ School of Management, Fujian University of Technology, No 3, Xueyuan Road, Fuzhou, Fujian 350000, China
}

\begin{abstract}
College Students' employment is important because it involves human capital and social capital. The human capital and social capital of college students directly affects their quality of employment but the root is the parents' human capital. Empirical analysis shows that the effect of the father's educational level on the monthly wage of College Students' children is significant at a level of 5\% and the direction is positive. The effect of the mother's educational level on the monthly wage of College Students' is also significant at a level of $5 \%$, with a positive direction and the effect coefficient is greater than that for the father. Therefore, the equalization of educational opportunities is related to the life of one generation and to the growth of several generations. On-the-job education and lifelong education also play an important role in improving the quality of life for the offspring.
\end{abstract}

\section{Introduction}

According to the employment report for Chinese college studentsreleased by MyCOS Research Institute, a thirdparty social survey organization, the employment rate for 2018 university graduates is $91.5 \%$. The employment rate of undergraduatescontinues to decline slowly, 1.6 percentage points less than the figure for 2014, and the proportion of employed 2018 undergraduate graduates is $73.6 \%$, which continues to decline for five consecutive years. The number of graduates in 2020 will reach 8.74 million, which is an increase of 400000 over the previous year. The employment situation for 2020 graduates who are affected by the Corona epidemic situation is more bleak. Therefore, the employment and employment quality of college students is important for the state and society. This study uses big data to interpret the problems that affect the quality of College Students'employment.

\section{Theoretical analysis of the effect of parents' educational level on the employment quality of College Students}

The concepts of human capital and social capital are used to analyze College Students' employment quality. Human capital theory states thateducational level, knowledge structure, skill level and experience accumulation affect an individual's income and working conditions and employment quality. Social capital theory states that the acquisition and utilization of personal social network resources affects personal income and working conditions and affects employment quality. According to the theory of human capital, if the labor market is completely competitive, the more human capital an individual has, the greater is the ability to work, the greater is the value that is created for the enterprise and the greater is the remuneration for the individual.

Xie Yong and others all empirically studied the relationship between human capital characteristics and the employment quality of college students(Xie Yong,2009; Meng Dahu,2012; Yue Dejun,2016; Qin Yin,2017)[1-4]. Social capital theory focuses on the role of social capital in the quality of College Students' employment. Granovetter and Nan respectively proposed a weak relationship theory and social resource theory and Bian studied the effect of strong relationship power on job hunting(Granovetter,1973;Nan,1999)[5,6].Xue Zaixing and others studied the relationship between social capital and the employment quality of college students(Xue Zaixing,2014; Liu Jie,2016; Zhao Jianguo,2017; Liu yanru,2018)[7-10].Some studies differentiate between human capital and social capital. $\mathrm{Xu}$ Taoand $\mathrm{Hu}$ Jianguo studiedthese two types ofcapital(Xu Tao,2016; $\mathrm{Hu}$ Jianguo,2019)[11,12]. However, there is no consensus on which type of capital has a greater impact on the employment quality of college students.

These studies involve the quality of College Students' employment. Human capital, social capital, or a differentiation of the two uses empirical analysis but the reason for the different approaches is unclear. This study analyzes the quality of their children's employment from the perspective of parents to determine the source of the

\footnotetext{
*dxy@fjut.edu.cn
} 
quality of College Students' employment and improve the quality of College Students' employment.

\section{Data collection and research methods}

\section{1 data collection}

This study uses the national dynamic monitoring database of floating population (CMDS) for 2016. The database contains data from 433 regions of 32 provinces in China, with a total of 1690000 samples. 26919 samples were obtained, including 13359 males and 13560 females.

\section{2 research variables and research methods}

This paper determines the effect mechanism for parents' educational level on the employment quality of college students. The dependent variable is the quality of College Students' employment, which is measured by the economic index of income. The monthly wage for College Students' employment is the dependent variable. The independent variable is the educational level of parents, which is assigned according to whether they attended primary school, junior high school, high school/secondary school, college, undergraduate and graduate students. The employment quality of college students is also affected by personal characteristics and occupation-related characteristics, so gender, age, household registration, whether they are Party members, occupation type, contract formality and other indicators are used as control variables. This study hypothesizes that the educational level of parents has a significant impact on the employment quality of College Students.

It is expressed by the formula: Income $i=a+\beta e d u \_f_{i}+\gamma X_{i}+\varepsilon$

Incomei represents the employment quality of college students, which is the monthly wage level; edu_firepresents the educational level of the parents; $\mathrm{X}_{\mathrm{i}}$ represents the control variable; ais a constant, $\beta$ is thecoefficient for the independent variableedu_f and the dependent variable income, $\gamma$ is the coefficient for the control variable $\mathrm{X}$ and the dependent variable income and cis a randomerror.

\subsection{Analysis of descriptive statistics}

An analysis of the sample size, error, mean value, minimum value and maximum value for these nine variables is shown in Tab.1.

Table 1. Descriptive Analysis of Variables

\begin{tabular}{llllll}
\hline Variable & Obs & Mean & Std. Dev. & Min & Max \\
\hline income & 23091 & 5281.57 & 4759.473 & 100 & 90000 \\
father_edu & 2409 & 3.210046 & 0.9176465 & 1 & 7 \\
mother_edu & 2899 & 2.879269 & 0.9220375 & 1 & 7 \\
gender & 26919 & 0.4962666 & 0.4999953 & 0 & 1 \\
age & 26919 & 31.08774 & 7.629747 & 17 & 86 \\
household & 26919 & 0.5116832 & 0.4998728 & 0 & 1 \\
party & 26883 & 0.1433248 & 0.3504103 & 0 & 1 \\
occupation & 22950 & 40.13081 & 17.11863 & 10 & 80 \\
contract & 18280 & 0.8556893 & 0.3514141 & 0 & 1 \\
\hline
\end{tabular}

The monthly salary of college students is variable, but the average monthly salary is 5281 yuan. The average educational level of the father is greater than junior high school and that of the mother is close to junior high school. The father's educational level and the mother's educational level have a strong correlation with college students' monthly salary.

\section{The effect of parents' educational level on the employment quality of College Students}

\subsection{Analysis of Results}

Linear regression analysis is used to obtain the regression results in Tab.2:

Table 2. Empirical results of intergenerational transmission of Education

\begin{tabular}{ccccccc}
\hline & $(1)$ & $(2)$ & $(3)$ & $(4)$ & $(5)$ & $(6)$ \\
VARIABLES & Income & Income & Income & Income & Income & Income \\
\hline father_edu & $447.6^{* * *}$ & $316.0^{* * *}$ & $231.7 * *$ & $211.7^{* *}$ & $180.7^{*}$ & $197.6^{* *}$ \\
& $(96.15)$ & $(90.69)$ & $(94.71)$ & $(94.96)$ & $(96.81)$ & $(79.98)$ \\
gender & $1,307^{* * *}$ & $593.3^{* * *}$ & $613.6^{* * *}$ & $608.4^{* * *}$ & $625.3^{* * *}$ & $521.5^{* * *}$
\end{tabular}


(175.3)

age

household

party

occupation

contract
(170.4) $252.1 * * *$ $273.3 * * *$

(17.23)

(18.58)

$-578.0^{* * *}$

(191.5)

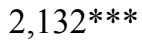

(337.9)

1,879

Observations

0.038

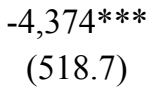

0.152
R-squared

0.156
(170.6)

$250.7^{* * *}$

(173.8)

$244.0 * * *$

(19.19)

$-578.2 * * *$

(197.2)

$517.2^{* *}$

(263.6)

$-7.981$

(5.160)

(192.1)

(256.6)

$890.5^{* * *}$

(173.6)

(17.16)

$-482.6^{* * *}$

(166.2)

$569.4^{* *}$

(221.5)

$-11.96^{* * *}$

$-2,241 * * *$

(612.9)

$\begin{array}{cccc}(649.4) & (650.6) & (720.4) & (612.9) \\ 1,879 & 1,874 & 1,834 & 1,397\end{array}$

0.158

Standard errors in parentheses, ${ }^{* * *} \mathrm{p}<0.01,{ }^{* *} \mathrm{p}<0.05,{ }^{*} \mathrm{p}<0.1$

The first column of this table shows the effect of the father's educational level on the monthly wage of College Students. The second column shows the effect after adding the control variable of gender. The third,fourth, fifth and sixth columns show the regression results after adding age, household registration, whether they are Party members, occupation and whether a contract is involved. With the control variables, the effect is still significant at the $5 \%$ level, so if the parents' educational level increases by one level (such as from primary school to junior high school), the monthly salary of college students increases by 197.6 yuan.

\subsection{Robustness test}

In order to verify the robustness of the results of the effect of parents' educational level on children's monthly wage, this study uses the mother's educational level as the independent variable. Itseffect on the monthly wage of the children is significant and the direction is consistent, which shows that the effect of parental educational level on children's monthly wage is stable, as shown in Tab.3:

Table 3. Analysis of robustness for intergenerational transmission of education

\begin{tabular}{ccccccc}
\hline VARIABLES & $\begin{array}{c}(1) \\
\text { Income }\end{array}$ & $\begin{array}{c}(2) \\
\text { Income }\end{array}$ & $\begin{array}{c}(3) \\
\text { Income }\end{array}$ & $\begin{array}{c}(4) \\
\text { Income }\end{array}$ & $\begin{array}{c}(5) \\
\text { Income }\end{array}$ & $\begin{array}{c}(6) \\
\text { Income }\end{array}$ \\
\hline mother_edu & $361.0^{* * *}$ & $368.8^{* * *}$ & $272.6^{* *}$ & $267.8^{* *}$ & $246.8^{* *}$ & $232.1^{* *}$ \\
& $(112.9)$ & $(105.2)$ & $(110.3)$ & $(110.9)$ & $(112.9)$ & $(93.11)$ \\
gender & $1,730^{* * *}$ & $827.8^{* * *}$ & $853.6^{* * *}$ & $848.8^{* * *}$ & $880.7^{* * *}$ & $683.9^{* * *}$ \\
& $(210.3)$ & $(201.6)$ & $(201.5)$ & $(202.0)$ & $(205.4)$ & $(169.6)$ \\
age & & $361.6^{* * *}$ & $338.1^{* * *}$ & $340.6^{* * *}$ & $332.4^{* * *}$ & $272.4^{* * *}$ \\
& & $(19.21)$ & $(20.89)$ & $(21.08)$ & $(21.55)$ & $(18.82)$ \\
household & & & $-634.4^{* * *}$ & $-619.5^{* * *}$ & $-616.2^{* * *}$ & $-530.5^{* * *}$ \\
& & & $(222.9)$ & $(223.7)$ & $(228.9)$ & $(188.9)$ \\
party & & & & 75.15 & 26.45 & 274.6 \\
& & & & $(295.1)$ & $(301.9)$ & $(247.5)$ \\
occupation & & & & & $-15.98^{* * *}$ & $-21.15^{* * *}$ \\
& & & & & $(5.975)$ & $(4.587)$ \\
contract & & & & & & $1,020^{* * *}$ \\
& & & & & & $(208.9)$ \\
Constant & $2,883^{* * *}$ & $-6,575^{* * *}$ & $-5,295^{* * *}$ & $-5,373^{* * *}$ & $-4,429 * * *$ & $-3,685^{* * *}$ \\
& $(371.8)$ & $(610.2)$ & $(757.5)$ & $(761.1)$ & $(837.4)$ & $(695.9)$ \\
Observations & 2,321 & 2,321 & 2,321 & 2,315 & 2,272 & 1,744 \\
R-squared & 0.030 & 0.159 & 0.162 & 0.162 & 0.163 & 0.242 \\
\hline
\end{tabular}

Standard errors in parentheses $, * * * \mathrm{p}<0.01, * * \mathrm{p}<0.05, * \mathrm{p}<0.1$ 


\section{Conclusion and suggestions}

College Students' employment quality depends most on the human capital of the parents. The educational level of the parents has a significant impact on children's monthly wage level. The father's educational level and the mother'seducational level show the same direction and trend. This shows that the equalization of educational opportunities is related to the lives of several generations.

Educational opportunities should be equalized and this policy should be promotedmore in rural and urban areas. All types of in-service education and lifelong education should also be promoted because the accumulation of this human capital affectssuccessive generations.

Due to the availability of data, this study only deals with education, which is an indicator of human capital. Future research might determine other elements of human capital.

\section{Acknowledgement}

The authors acknowledge the support of the Junior Teachers Education and Research Project of the Education Department of Fujian Province (JAS170301).

\section{Reference}

1. Yong X and Yapu Z 2009 J. South China Population 24 pp49-56.

2. Dahu M, Lifeng S and Lu L 2012 J. Population \& Economics 3 pp 19-26.

3. Dejun Y and Yuan T 2016 J. Jiangsu Higher Education 1 pp 101-104.

4. Yin Q 2017 J. Journal of Guangxi University for Nationalities (Philosophy and Social Science Edition) 39 pp 127-133.

5. Granovetter M S 1973 J. American Journal of Sociology 78 pp 1360-1380.

6. Nan L 1999 J. Annual Review of sociology 25 pp 467-487.

7. Zaixing X 2014 J. Research of Youth 3 pp 55-64.

8. Jie L and Wei H 2016 J. Statistics \& Decision 12 pp 110-114.

9. Jianguo $\mathrm{Z}$ and Jiaqing W $2017 \mathrm{~J}$. Research on Financial and Economic Issues 6 pp 124-131.

10. Yanru L, Shuhan S and Haiyu G 2018 J. Social security studies 4 pp29-37.

11. Tao X 2016 J. Journal of China University of Labor Relations 30 pp62-64.

12. Jianguo H and Yu P 2019 J. Contemporary Youth Research 5 pp 109-116. 